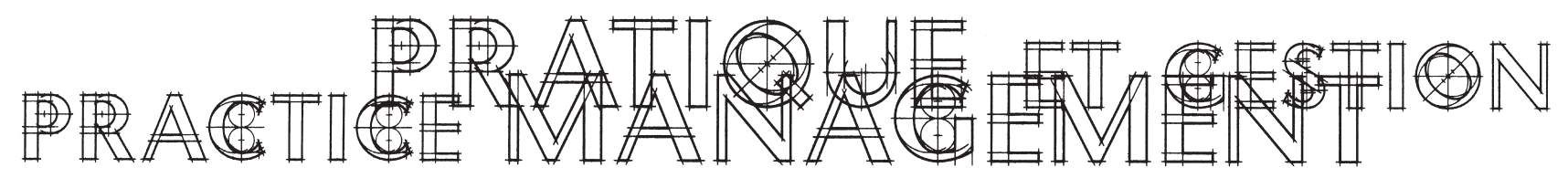

\title{
Take Your Practice to the Next Level - Part 2
}

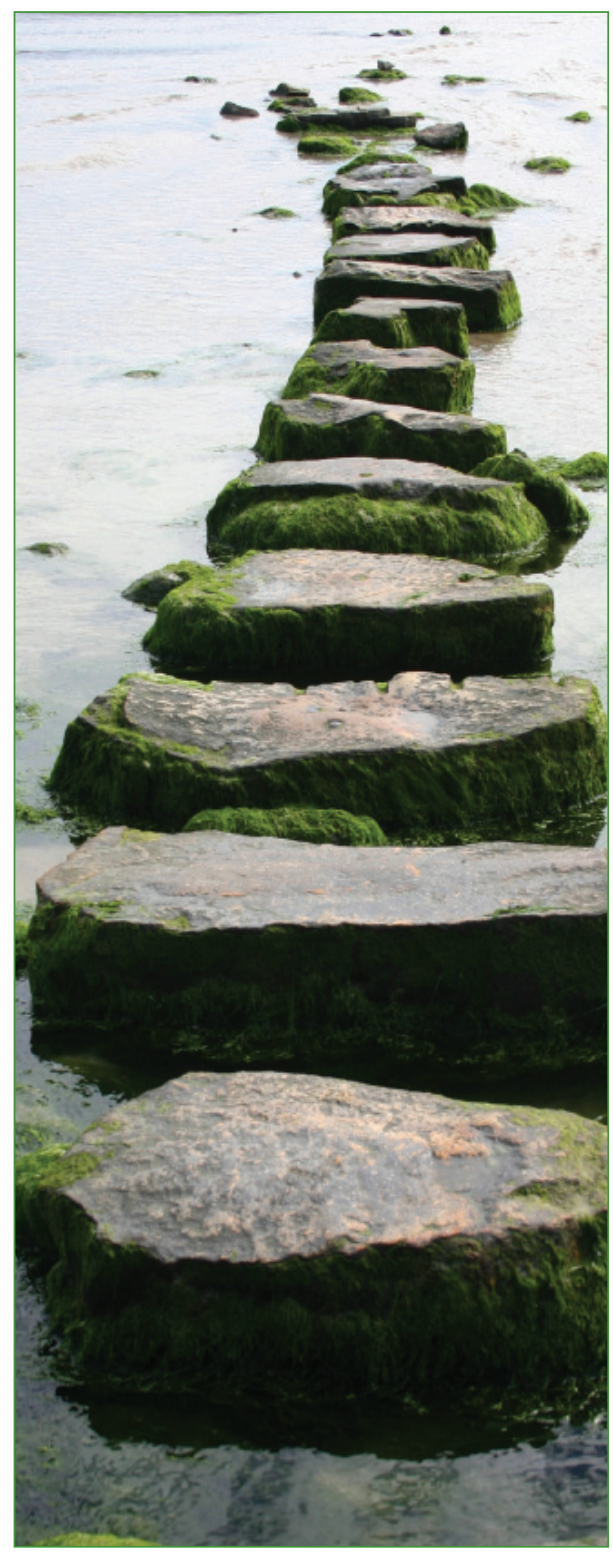

Tn my last article I laid the groundwork for why some optometrists fail to take their L practices to the next level of success. I drew parallels from Michael Gerber's book "The EMyth Revisited".

It proposes that there are three personality traits needed for success, namely: entrepreneur, manager and technician. The entrepreneur being the idea person, responsible for goal setting and watching the horizon for a competitive advantage. The manager as the one to put processes in place, to set rules and guidelines for the business to follow so a consistent service or product will be delivered to the customer. The technician as the doer of the group, the one who gets the job done.

Each has defined responsibilities that are needed at various times and in various measures during the life of a business. However most business fail, or under perform, because one of these traits usually dominants, leaving the other two underdeveloped. In optometrists, like most business owners, this dominant trait tends to be the technician.

When the practice gets busy, the optometrist concentrates on the technician role of taking care of patients needs, leaving the roles of entrepreneur and manager to suffer. All these roles are absolutely necessary if you wish to move your practice forward and to a higher level.

Gerber suggests that the best way to overcome this is to design your practice as if you were going to franchise it. He calls this design-

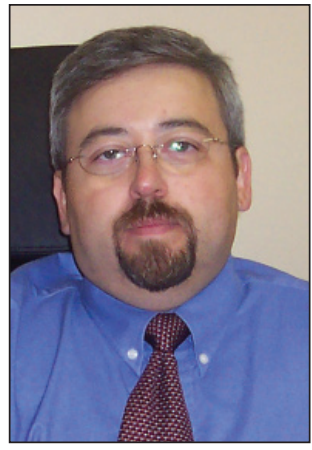

Alphonse Carew $\mathrm{BSC}, \mathrm{OD}, \mathrm{MBA}$

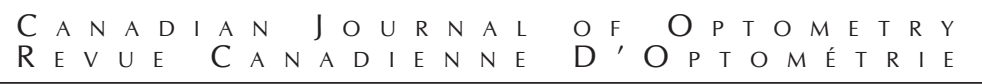




\section{PRACTICE MANAGEMENT

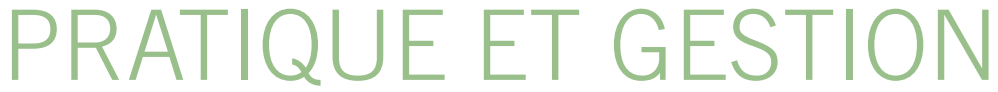

ing your Franchise Prototype. Simply pretend you are going to open 5000 more just like it. You are not likely to ever actually franchise your office but going through the steps as if you were, forces you to look seriously at how you are running your practice. An interesting statistic he quotes says that $80 \%$ of businesses fail in the first 5 years, whereas $75 \%$ of franchises succeed.

It is thought that the success of the franchise stems from the systems that are developed in order for customers to have the same high quality experience at every location. The systems run the business and people run the systems. This could be true for you practice as well.

With the technician-type of personality you may be tempted to design your practice from the bottom-up. Knowing what actions are needed to serve your patients you may feel that is the best place to start, but the better tactic is a top-down approach. Start with your entrepreneur perspective.

Start with a picture of your dream practice. How do you see your practice fitting best in the competitive environment it finds itself? How will it fulfill it's primary objective to find and retain patients? What would a great practice look like? One that produces outstanding results for your patients, and thus profits for you. Look at it from the perspective of how the patient wants the experience to look and feel, not how you (the technician) wants it to look and feel. Be more concerned with how things are done in your office than exactly what things are done at this point. With your entrepreneurial vision work back to the present to determine what needs to be changed in your present reality to meet that vision.

With your vision in place the next step is to use your

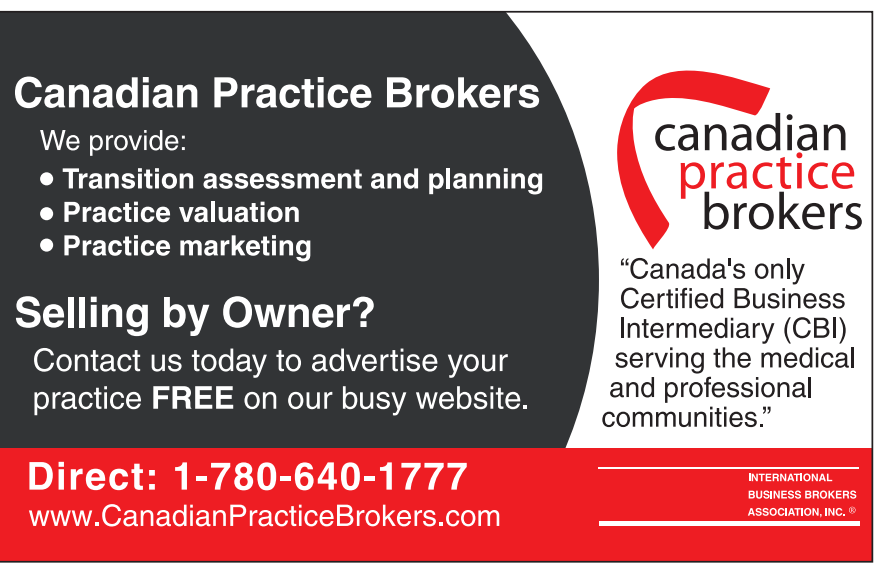

management perspective to set-up the systems that are needed to provide the high quality and consistent care that fulfills your dream for an ideal practice. Again pretend that you are going to franchise your practice 5000 times. This puts you in the right state of mind to generate the systems to deliver the care you wish. These operational systems need to be detailed and written in an operations manual that all employees can referred to it, especially at the time of being hired. This is a daunting task at first but once in place it only needs to be reassessed when competitive forces and/or your entrepreneur vision changes.

With the right systems in place ordinary people can produce extraordinary results. Think about the consistency and quality of service provided by your local fast food chain who hires mainly high school students, all done with clear operations manuals. In the optometric practice you don't always need brilliant staff (or doctors for that matter) but good staff with the best systems to produce exquisite results. Make sure your people understand the idea behind the work they are asked to do and the manner they are being asked to perform (from the operations manual) with the ultimate goal of helping the practice fulfill its vision.

Having developed the vision for your practice and having generated the systems that will produce the results you wish, you now can turn back to the technician role, the one you are most comfortable with. In the long run you will need to revisit the other roles from time to time, especially the entrepreneur role to make sure you are still on the right track of growing your practice and reaching those higher levels.

\section{FOR SALE / LEASE \\ Optometric Practice and Optical (Licensed Optician)}

20 Townsend Street,Sydney

Nova Scotia B1P 6V2

Work \#'s 902-564-5332 and 902-564-8330

Fax\# 902-564-4920

E-mail drbmiller@syd.eastlink.ca

Web: www.drbmiller.com

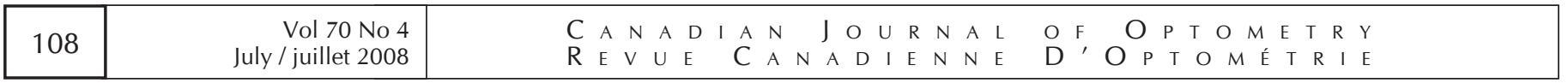

